\title{
Costs of Necrotizing Enterocolitis and Cost-Effectiveness of Exclusively Human Milk-Based Products in Feeding Extremely Premature Infants
}

\author{
Vaidyanathan Ganapathy, Joel W. Hay, and Jae H. Kim²
}

\begin{abstract}
Objective: This study evaluated the cost-effectiveness of a 100\% human milk-based diet composed of mother's milk fortified with a donor human milk-based human milk fortifier (HMF) versus mother's milk fortified with bovine milkbased HMF to initiate enteral nutrition among extremely premature infants in the neonatal intensive care unit (NICU). Methods: A net expected costs calculator was developed to compare the total NICU costs among extremely premature infants who were fed either a bovine milk-based HMF-fortified diet or a $100 \%$ human milk-based diet, based on the previously observed risks of overall necrotizing enterocolitis (NEC) and surgical NEC in a randomized controlled study that compared outcomes of these two feeding strategies among 207 very low birth weight infants. The average NICU costs for an extremely premature infant without NEC and the incremental costs due to medical and surgical NEC were derived from a separate analysis of hospital discharges in the state of California in 2007. The sensitivity of cost-effectiveness results to the risks and costs of NEC and to prices of milk supplements was studied.

Results: The adjusted incremental costs of medical NEC and surgical NEC over and above the average costs incurred for extremely premature infants without NEC, in 2011 US\$, were $\$ 74,004$ (95\% confidence interval, $\$ 47,051-\$ 100,957)$ and $\$ 198,040(95 \%$ confidence interval, $\$ 159,261-\$ 236,819)$ per infant, respectively. Extremely premature infants fed with $100 \%$ human milk-based products had lower expected NICU length of stay and total expected costs of hospitalization, resulting in net direct savings of 3.9 NICU days and $\$ 8,167.17$ (95\% confidence interval, $\$ 4,405-\$ 11,930)$ per extremely premature infant $(p<0.0001)$. Costs savings from the donor HMF strategy were sensitive to price and quantity of donor HMF, percentage reduction in risk of overall NEC and surgical NEC achieved, and incremental costs of surgical NEC.

Conclusions: Compared with feeding extremely premature infants with mother's milk fortified with bovine milk-based supplements, a 100\% human milk-based diet that includes mother's milk fortified with donor human milk-based HMF may result in potential net savings on medical care resources by preventing NEC.
\end{abstract}

\section{Introduction}

I NFANTS WHO ARE BORN extremely premature (EP) at $\leq 28$ weeks of gestational age have an immature gastrointestinal system that puts them at higher risk for necrotizing enterocolitis (NEC), an acute inflammatory condition of the bowel that affects $6-7 \%$ of all premature infants with birth weights of $<1,250 \mathrm{~g}$ and is also one of the leading causes of mortality among these infants. ${ }^{1-4}$ The American Academy of Pediatrics recommends initiating mother's own milk early during feeding of EP infants owing to the important health benefits that mother's milk has to offer, including protection against
NEC. ${ }^{5-8}$ Very often, though, mother's milk is not available in sufficient quantities to premature infants, thereby limiting the availability of this beneficial milk source. ${ }^{9}$ Donor human milk is an available proxy for mother's milk. It is believed that donor milk might be offering putative benefits of preventing NEC, by supplying immunoprotective factors to the immature gut mucosa. ${ }^{10,11}$ However, it may be possible that the protective effect is due to the absence of harmful antigens rather than the presence of beneficial agents. A randomized controlled study by Schanler et al., ${ }^{12}$ comparing donor human milk to preterm formula, did not find a significant protective effect of donor human milk on NEC, but a significant

\footnotetext{
${ }^{1}$ Department of Clinical Pharmacy \& Pharmaceutical Economics \& Policy, University of Southern California, Los Angeles, California.

${ }^{2}$ Department of Pediatrics, University of California San Diego, San Diego, California.
} 
difference in the study's protocol was that it involved fortification of donor milk with bovine milk-based human milk fortifier (HMF). Nevertheless, the study also noted a protective effect of mother's own milk on NEC. This study may have been confounded by the presence of negative effects of exposure to bovine milk products.

In another randomized controlled study using an intent-totreat analysis, Sullivan et al. ${ }^{13}$ compared outcomes of fortifying mother's milk using a human milk-based HMF, Prolact $+\mathrm{H} 2 \mathrm{MF}^{\mathrm{TM}}$ (Prolacta Bioscience, Monrovia, CA), versus fortification using bovine milk-based HMF among 207 very low birth weight infants $(<1,250 \mathrm{~g})$ in the neonatal intensive care unit (NICU). Thus far, this is the only study that compared the outcomes of fortifying mother's milk using bovine milkbased HMF versus donor human milk-based HMF. The duration of study was the earliest among the following milestones achieved: discharge of the infant, 91 days of age, or attainment of $50 \%$ oral feedings per day. Infants in both the groups received mother's own milk when enteral nutrition was initiated. However, they differed in the type of HMF used for fortifying mother's milk to which they were randomized-receiving either bovine milk-based HMF (BOV arm) or human milk-based HMF (HUM arm) —and the type of nutritional supplementation given when mother's milk was no longer available (viz., preterm formula in the $\mathrm{BOV}$ arm and pasteurized donor human milk in the HUM arm). It was observed in that study that infants in the HUM arm $(n=138)$ had significantly lower incidence of overall NEC and surgical NEC than infants in the BOV arm $(n=69)$ : eight of 138 versus 11 of $69(p=0.02)$ and two of 138 versus seven of $69(p=0.007)$ in the HUM versus BOV arms for overall NEC and surgical NEC, respectively. After controlling for confounding factors, infants in the HUM arm were found to have a $77 \%$ reduction in the odds of developing NEC (odds ratio $=0.23,95 \%$ confidence interval $[\mathrm{CI}]$ $0.08,0.66)$ compared with infants in the BOV arm. Major strengths of the study of Sullivan et al. ${ }^{13}$ were that the study was randomized, the stratification scheme achieved a balance of patient characteristics across the study groups, and there was good adherence to the study protocol. The study was, however, limited in power to examine subgroups by sex or birth weight, and its sample may or may not be representative of the universe of NICUs across the United States. The study of Sullivan et al., ${ }^{13}$ however, suggests that beyond the positive biologic benefits of human milk, there may be factors in bovine milk products that negatively affect the premature intestine.

In the light of these results the current article analyzes the cost-effectiveness of using a 100\% human milk-based diet that involves fortifying mother's milk with human milk-based HMF versus using a bovine milk-based HMF-fortified diet to initiate enteral nutrition among EP infants in the NICU.

An important secondary objective of this article was to estimate the average NICU costs of medical and surgical NEC among EP infants in a separate analysis using hospital discharge database analysis.

\section{Subjects and Methods}

A net expected cost calculator for initial NICU hospitalization expenses among EP infants was developed in Microsoft (Redmond, WA) Excel 2003, to compare total expected NICU costs among infants who either received a donor human milk-based HMF-fortified diet (HUM arm) or a bovine milk-based HMF-fortified diet (BOV arm). The parameters used to develop this calculator include the following: (1) probabilities of overall NEC and surgical NEC in each group (HUM arm vs. BOV arm), obtained from the study of Sullivan et al., ${ }^{13}$ (2) quantities and prices of HMFs used in each group, (3) quantities and prices of donor human milk and preterm formula used (when mother's milk was no longer available to infants) in the HUM and BOV arms, respectively, and (4) incremental costs of medical and surgical NEC over and above average NICU costs incurred for an EP infant without NEC. Table 1 provides a summary of the parameters 1,2 , and 3 as obtained from the randomized trial study. ${ }^{13}$

As summarized in Table 1, all infants in the study (BOV and HUM arms) received some amount of mother's milk, providing more than $70 \%$ of total enteral intake, that was fortified using either bovine milk-based HMF or donor human milkbased HMF depending on to which group the infants were randomized. Mother's milk was supplemented with preterm formula in the BOV arm and donor human milk in the HUM arm only when there was an insufficient amount of mother's own milk. The price of Prolact $+\mathrm{H} 2 \mathrm{MF}(\$ 6.25 / \mathrm{mL})$ was obtained from the manufacturer (Prolacta Bioscience). For the price of donor human milk (20 cal/oz) we conservatively used the price charged by nonprofit milk banks, a $\$ 3.00$ charge per ounce of donor milk for processing and handling charges, that was obtained from the Human Milk Bank Association of North America milk bank in San Jose, CA (pricing provided by the Association). Infants in both groups received own mother's milk, and hence any resources utilized in the collection and storage of expressed breastmilk are assumed to be the same in both groups. (Also, it should be noted that any difference in quantities of own mother's milk between the two groups would actually be compensated for by the amount of supplements used and so are accounted for in the calculator.) For the bovine milk-based HMF and preterm formula usage in the study we conservatively applied the lowest commercial prices available online as follows: (a) bovine HMF, Similac ${ }^{\circledR}$ (Abbott Laboratories, Abbott Park, IL) HMF 50-pack, 0.9-g packets, \$54.00 (source, Abbottstore.com/Similac HMF), and Enfamil $^{\circledR}$ (Mead Johnson, Evansville, IN) HMF 100-pack, 0.7g packets, \$149.99 (source, BabyWuvinc.com/Enfamil HMF), which gives an average price of $\$ 1.30$ per packet; and (b) ready-to-use preterm formula, Enfamil premature $20 \mathrm{cal} / \mathrm{oz}$, six (2-fl oz) bottles, \$10.00 (source: Drugstore.com/Enfamil Premature 20), and Enfamil premature $24 \mathrm{cal} / \mathrm{oz}$, six (2-fl oz) bottles, \$14.13 (source, Drugstore.com/Enfamil Premature $24)$, to get an average price of $\$ 1.00$ per oz $(\$ 0.03 / \mathrm{mL})$.

To estimate the average hospitalization costs among EP infants without NEC and the average incremental costs of medical and surgical NEC cases, we conducted multivariate analyses on hospital discharge data collected during the year 2007 in the state of California, obtained from the Office of Statewide Health Planning \& Development (OSHPD). Preparation of the analytic sample for cost analysis, consisting of discharges from among EP infants without NEC versus those among infants with medical NEC and with surgical NEC, from the OSHPD 2007 database, is explained as follows.

\section{Analysis of NEC costs}

EP infant discharges among the 2007 OSHPD data were identified by International Classification of Diseases, $9^{\text {th }}$ 
Table 1. Summary of Parameters Used in the Cost-Effectiveness Model Comparing the Two Feeding Strategies - Mother's Milk Fortified with Bovine Milk-Based Versus Human Milk-Based Human Milk Fortifier-Among Very Low Birth Weight Infants $(\leq 1,250 \mathrm{G})$

\begin{tabular}{|c|c|c|}
\hline \multirow[b]{2}{*}{ Constituent of the diet } & \multicolumn{2}{|c|}{ Median quantity } \\
\hline & $B O V \operatorname{arm}(\mathrm{n}=69)$ & HUM arm $(\mathrm{n}=138)$ \\
\hline Mother's own milk & $5,676 \mathrm{~mL}$ & $4,432 \mathrm{~mL}$ \\
\hline $\begin{array}{l}\text { Human milk fortifier } \\
\left(25^{\text {th }}, 75^{\text {th }} \text { percentiles }\right)^{\mathrm{a}}\end{array}$ & 128 packets $(25,277)$ & $1,650.8 \mathrm{~mL}(915,2,528)$ \\
\hline Preterm formula ${ }^{\mathrm{b}}$ & $961 \mathrm{~mL}$ & - \\
\hline Donor human milk ${ }^{c}$ & - & $39.5 \mathrm{~mL}$ \\
\hline \multicolumn{3}{|l|}{ Probability of NEC } \\
\hline Overall incidence & 0.16 & $0.06^{\mathrm{d}}$ \\
\hline Surgical incidence & 0.10 & $0.01^{\mathrm{e}}$ \\
\hline Average price per unit & Bovine HMF: $\$ 1.30$ per packet & Prolact+H2MF: $\$ 6.25 / \mathrm{mL}$ \\
\hline of milk products used & Preterm formula: $\$ 0.03 / \mathrm{mL}$ & Donor human milk: $\$ 0.10 / \mathrm{mL}$ \\
\hline
\end{tabular}

The BOV arm comprised mother's milk fortified with bovine milk-based human milk fortifier (HMF), and the HUM arm comprised mother's milk fortified with donor human milk-based HMF.

${ }^{a}$ For fortifying mother's milk, Enfamil/Similac bovine human milk fortifier packets were used in the BOV arm, and Prolact+H2MF was used in the HUM arm.

${ }^{\mathrm{b}}$ Fifty-three of the 69 infants in the BOV arm received some preterm formula when their mothers were unable to provide sufficient breastmilk.

${ }^{c}$ Eighty-two of the 138 infants in the HUM arm received some donor human milk when their mothers were unable to provide sufficient breastmilk.

${ }^{\mathrm{d}}$ Percentage reduction in risk of overall necrotizing enterocolitis (NEC) versus BOV arm, $63 \%$; $p$ value for difference in incidence of NEC between BOV and HUM arms, 0.02 .

ePercentage reduction in risk of surgical NEC versus BOV arm, $86 \%$; $p$ value for difference in incidence of surgical NEC between BOV and HUM arms, 0.007 .

Revision (ICD-9) diagnosis codes 765.0 (765.21-765.24). Diagnosis of NEC was identified using ICD-9 codes 777.50-777.53 and NEC records with one or more of the following surgical procedures: Exploratory laparotomy, bowel resection, stoma creation, and intestinal anastomosis (all identified by ICD-9 procedure codes ${ }^{14}$ ) were classified as surgical NEC discharges to differentiate from NEC cases that did not require surgical management. Discharges from hospitals that did not report charges (approximately 12\% of discharges, mostly belonging to Kaiser Health Foundation hospitals) and discharges involving transfers (approximately 26\%) were excluded from analysis. Hospital specific cost-to-charge ratios were used to adjust charges to obtain actual costs. Discharges with an average daily cost of $<\$ 100$ (approximately $0.3 \%$ ) were considered improbable for premature infant stays and were excluded from analysis. As a final step in the data preparation, we excluded infants who died within the first 3 days of life. These infants were probably those born at gestational ages below the limit of viability, often dying because of causes other than NEC, and therefore not likely candidates to receive HMF therapy. All cost estimates were adjusted for inflation to 2011 US\$ using the Medical Component of the Consumer Price Index. ${ }^{15}$ Average estimates of length of stay and costs for an EP infant in the sample, with and without the last exclusion criterion (mortality at $<3$ days), were compared. We used the final sample that excluded infants who died within 3 days of life to obtain multivariate adjusted estimates for incremental costs of medical NEC and surgical NEC. Ordinary Least Squares regression was used to obtain the incremental effects of medical NEC and surgical NEC on hospitalization costs after adjusting for sex, race, payer status (Medicaid vs. private or other), mortality, and comorbid perinatal conditions including respiratory distress, other infections, anemia, jaundice, and endocrine, hemorrhagic, integumental, and other ill-defined conditions. We also developed multivariate models using the Generalized Estimating Equations framework, ${ }^{16}$ in which sample observations were weighted by predicted probability of NEC occurrence using the inverse probability weighting technique. ${ }^{17}$ Because the model coefficients did not vary significantly among the Ordinary Least Squares regression and weighted Generalized Estimating Equations models, we used the Ordinary Least Squares regression adjusted coefficients for medical and surgical NEC in the net cost calculator (explained earlier in this section) because of their direct interpretability as incremental costs over and above the costs of an infant without NEC.

\section{Sensitivity analyses}

The sensitivity of cost-effectiveness results was analyzed using one-way and two-way percentage changes in the parameters that were used to build the expected costs calculator. The impact of the following scenarios on cost-effectiveness were considered: (1) price and quantity of donor human milkbased HMF increased linearly; (2) both bovine HMF and preterm formula cost zero dollars to account for the possibility that manufacturers distribute free samples of bovine HMFs and preterm formulas in hospitals; and (3) percentage risk reductions of overall NEC and surgical NEC achieved by donor milk HMF strategy were less than observed for the base-case (two-way change).

\section{Results}

\section{Costs of NEC}

There were 2,560 EP infants in the final analytic sample derived from 2007 OSHPD data (see Appendix). Two hundred 
fifty-nine $(10 \%)$ of them had NEC, and 82 of these infants suffered from surgical NEC (3.2\%). Table 2 provides a summary of demographic and other baseline characteristics of the final analytic sample used for NEC cost analysis. Race was significantly associated with NEC status when missing data were included. The NEC groups had significantly higher rates of comorbid perinatal conditions such as respiratory distress and other respiratory conditions, infections, hemorrhage, and endocrine and other ill-defined perinatal conditions than the no NEC group. Also, there was a significantly higher rate of mortality before discharge among medical NEC and surgical NEC groups compared with the no NEC group (rates of $20.9 \%$, $23.2 \%$, and $10.6 \%$ among medical NEC, surgical NEC, and no NEC, respectively; $p<0.0001)$. The mean length of stay for an EP infant without NEC obtained from the final sample was 64.5 days, and the mean cost was $\$ 207,378$ in 2011 US\$ (Table 3). The multivariate adjusted estimates for the length of stay and cost of medical NEC over and above the cost for an EP infant without NEC are 11.7 days (95\% CI 6.9-16.5 days) and $\$ 74,004$ (95\% CI \$47,051-\$100,957), respectively. The corresponding adjusted incremental length of stay and cost estimate for surgical NEC are 43.1 days (95\% CI 36.3-50 days) and $\$ 198,040$ $(95 \%$ CI $\$ 159,261-\$ 236,819)$ respectively. Tables 3 and 4 also show that excluding infants who died within 3 days of life had a significant impact on the baseline costs of an EP infant without NEC but did not have a meaningful effect on the incremental costs of medical NEC and surgical NEC.

\section{Cost-effectiveness of HUM arm versus BOV arm feeding strategies}

The total expected NICU costs for an infant receiving exclusively human milk-based versus bovine milk-based HMFfortified diets are summarized in Table 5. Considering the risks and costs of medical NEC and surgical NEC, the total expected NICU costs for an infant fed with bovine-fortified

Table 2. Demographic and Baseline Characteristics of Extremely Premature Infants in the Final Sample Cohort Derived from the State of California Office of Statewide Health Planning \& Development 2007 Discharge Data

\begin{tabular}{|c|c|c|c|c|c|c|}
\hline \multirow[b]{2}{*}{ Baseline characteristic } & \multirow[b]{2}{*}{ Category } & \multirow[b]{2}{*}{ Total } & \multicolumn{3}{|c|}{$\mathrm{n}(\%)$} & \multirow{2}{*}{$\begin{array}{l}\mathrm{p} \text { value } \\
(2 \text {-sided })^{\mathrm{a}}\end{array}$} \\
\hline & & & No NEC & Medical NEC & Surgical NEC & \\
\hline$n$ & & 2,560 & 2,301 & 177 & 82 & \\
\hline \multirow[t]{3}{*}{ Sex } & Male & 1,110 & $1,003(43.6)$ & $74(41.8)$ & $33(40.2)$ & $0.0760^{*}$ \\
\hline & Female & 988 & $896(38.9)$ & $67(37.9)$ & $25(30.5)$ & \\
\hline & Unknown/missing & 462 & $402(17.5)$ & $36(20.3)$ & $24(29.3)$ & \\
\hline \multirow[t]{6}{*}{ Race/ethnicity } & Hispanic white & 565 & 499 (21.7) & $47(26.6)$ & $19(23.2)$ & $0.0173^{*}$ \\
\hline & Non-Hispanic white & 514 & $476(20.7)$ & $30(16.9)$ & $8(9.8)$ & \\
\hline & Black & 151 & $140(6.1)$ & $9(5.1)$ & $2(2.4)$ & \\
\hline & Asian & 110 & $100(4.3)$ & $6(3.4)$ & $4(4.9)$ & \\
\hline & Other & 509 & $466(20.3)$ & $31(17.5)$ & $12(14.6)$ & \\
\hline & Unknown/missing & 711 & $620(26.9)$ & $54(30.5)$ & $37(45.1)$ & \\
\hline \multirow[t]{3}{*}{ Payer status } & Private & 985 & $890(38.7)$ & $65(36.7)$ & $30(36.6)$ & 0.8915 \\
\hline & Medicaid & 1,167 & $1,042(45.3)$ & $84(47.5)$ & $41(50)$ & \\
\hline & Other/unknown & 408 & $369(16)$ & $28(15.8)$ & 11 (13.4) & \\
\hline Total deaths before discharge & Dead & 301 & $245(10.6)$ & $37(20.9)$ & $19(23.2)$ & $<0.0001^{*}$ \\
\hline Respiratory distress syndrome & Present & 1,816 & $1,617(70.3)$ & $142(80.2)$ & $57(69.5)$ & $0.0185^{*}$ \\
\hline $\begin{array}{l}\text { Other respiratory } \\
\text { conditions of newborn }\end{array}$ & Present & 2,089 & $1,862(80.9)$ & $159(89.8)$ & $68(82.9)$ & $0.0123^{*}$ \\
\hline $\begin{array}{l}\text { Infections specific to } \\
\text { perinatal period }^{c}\end{array}$ & Present & 1,395 & $1,202(52.2)$ & $132(74.6)$ & $61(74.4)$ & $<0.0001^{*}$ \\
\hline Neonatal hemorrhage & Present & 846 & $715(31.1)$ & $84(47.5)$ & 47 (57.3) & $<0.0001^{*}$ \\
\hline Neonatal jaundice & Present & 1,876 & 1,687 (73.3) & $133(75.1)$ & $56(68.3)$ & 0.5075 \\
\hline $\begin{array}{l}\text { Endocrine/metabolic } \\
\text { disturbances }\end{array}$ & Present & 1,184 & $1,026(44.6)$ & $106(59.9)$ & $52(63.4)$ & $<0.0001^{*}$ \\
\hline Anemia & Present & 1,951 & $1,740(75.6)$ & $143(80.8)$ & $68(82.9)$ & 0.1037 \\
\hline $\begin{array}{l}\text { Integument and temperature } \\
\text { regulation-related conditions }\end{array}$ & Present & 193 & $173(7.5)$ & $12(6.8)$ & $8(9.8)$ & 0.6956 \\
\hline $\begin{array}{l}\text { Other ill-defined } \\
\text { perinatal conditions }^{\mathrm{d}}\end{array}$ & Present & 1,631 & $1,448(62.9)$ & $126(71.2)$ & $57(69.5)$ & $0.0478^{*}$ \\
\hline
\end{tabular}

${ }^{\mathrm{a}} p$ value (2-sided) represents the significance of $\chi^{2}$ statistics obtained for the comparison of three groups-no NEC, medical NEC, and surgical NEC - at the 5\% significance level.

Other respiratory conditions of newborn included pneumonia, emphysema, apnea, chronic lung disease, etc. (identified by International Classification of Diseases, $9^{\text {th }}$ Revision (ICD-9) codes 770.0-770.9).

'Infections specific to perinatal period included congenital rubella, cytomegalovirus infections, septicemia, urinary tract infections, etc (771.0-771.8).

${ }^{\mathrm{d} O t h e r}$ ill-defined perinatal conditions included central nervous system conditions, cardiac dysrhythmias, periventricular leukomalacia, etc. (779.0-779.9).

*Significance at $p<.05$. 
Table 3. Neonatal Intensive Care Unit Days and Initial Average Hospitalization Costs

Among Extremely Premature Infants Without Necrotizing Enterocolitis in the State of California Office of Statemide Health Planning \& Development 2007 Data

\begin{tabular}{|c|c|c|c|c|c|c|c|c|}
\hline Sample & $\mathrm{n}$ (no NEC) & Label & $\begin{array}{c}25 \mathrm{th} \\
\text { percentile }\end{array}$ & Mean & Median & $\begin{array}{c}75^{\text {th }} \\
\text { percentile }\end{array}$ & $\begin{array}{c}95^{\text {th }} \\
\text { percentile }\end{array}$ & $\begin{array}{c}99^{\text {th }} \\
\text { percentile }\end{array}$ \\
\hline $\begin{array}{l}\text { Without excluding } \\
\text { early deaths }\end{array}$ & 3,005 & $\begin{array}{l}\text { LOS (days) } \\
\text { Costs (2011 US\$) }\end{array}$ & $\begin{array}{c}2 \\
10,402\end{array}$ & $\begin{array}{c}49.4 \\
159,473\end{array}$ & $\begin{array}{c}51 \\
109,208\end{array}$ & $\begin{array}{c}79 \\
233,584\end{array}$ & $\begin{array}{c}122 \\
517,972\end{array}$ & $\begin{array}{c}159 \\
836,777\end{array}$ \\
\hline $\begin{array}{l}\text { Final excluding deaths } \\
\text { within the first } \\
3 \text { days of life }\end{array}$ & 2,301 & $\begin{array}{l}\text { LOS (days) } \\
\text { Costs (2011 US\$) }\end{array}$ & $\begin{array}{c}39 \\
77,781\end{array}$ & $\begin{array}{c}64.5 \\
207,378\end{array}$ & $\begin{array}{c}65 \\
165,611\end{array}$ & $\begin{array}{c}88 \\
280,570\end{array}$ & $\begin{array}{c}129 \\
578,053\end{array}$ & $\begin{array}{c}164 \\
872,514\end{array}$ \\
\hline
\end{tabular}

LOS, length of stay.

diet versus human donor HMF-fortified diet were \$231,954 and $\$ 223,787$, respectively, resulting in net direct savings of $\$ 8,167$ (95\% CI $\$ 4,405-\$ 11,930 ; p<0.0001)$ per EP infant treated in the NICU by using the exclusively human milkbased feeding strategy. The corresponding expected NICU lengths of stay for the two strategies were 69.5 and 65.6 days, respectively (data not shown), resulting in the saving of 3.9 NICU days (95\% CI 3.25-4.58 days; $p<0.0001)$ per EP infant using the HUM arm feeding strategy. Sensitivity of net savings to $10 \%$ changes in various model parameters is depicted in Figure 1. Costs savings from the human milk-based HMF fortification strategy decreased linearly with the increase in price or quantity of human milk-based HMF. A 50\% increase in the price (to $\$ 9.375 / \mathrm{mL}$ ) of Prolact $+\mathrm{H} 2 \mathrm{MF}$ resulted in net savings of $\$ 2,967$ for the HUM arm feeding strategy. Fortification using donor milk HMF was no longer a cost saving option when its price exceeded $\$ 11.19 / \mathrm{mL}$ (a $78 \%$ increase from the current price). A zero dollar price on both bovine HMF and preterm formula did not appreciably affect the cost savings $(\$ 7,972$, which is a $2 \%$ decrease from the original estimate), showing that net savings are not affected by changes in the prices of bovine milk products. Cost savings were sensitive to changes in the degree of risk reduction in overall NEC and surgical NEC achieved by the HUM arm feeding strategy and incremental costs of surgical NEC, with elasticity ratios of $>1$. With other parameters held fixed, a minimum $54 \%$ percentage risk reduction in both overall NEC and surgical NEC would have to be achieved by the donor HMF strategy in order to remain cost-effective (the net savings being \$3,039.57 per EP infant treated in the NICU).

\section{Discussion}

The cost-effectiveness analysis presented in this article serves to demonstrate to the neonatal community the value of preventing NEC, which is a serious and potentially lifethreatening neonatal gastrointestinal complication among EP infants. Management of NEC could be highly resource intensive, requiring greater length of NICU stay. Often respiratory and circulatory support is provided in severe cases, and about a third of infants affected with NEC require surgical intervention. ${ }^{3,18}$ In our analysis, using California statewide discharge data from over 257 hospitals, we found that after adjusting for potential confounders, EP infants with medical NEC stayed in the hospital for an additional 11.7 days and incurred additional costs of US\$ 74,004 compared with EP infants without NEC; infants with surgical NEC stayed for an additional 43.1 days and incurred additional costs of US\$198,040 compared with the average EP infant without NEC. Initiating enteral nutrition among EP infants by feeding mother's milk has been shown to be highly beneficial for these infants and to offer protection against NEC. ${ }^{6-8,11,19,20}$ Researchers have observed a threshold effect of human milk in the reduction of incidence of NEC. ${ }^{5,6,21,22}$ Key findings of the randomized controlled study conducted by Sullivan et al. ${ }^{13}$ are that a $100 \%$ human

Table 4. Multivariate Adjusted Incremental Costs and Length of Stay for Medical and Surgical Necrotizing Enterocolitis in the State of California Office of Statewide Health Planning \& Development 2007 Hospital Discharge Sample

\begin{tabular}{|c|c|c|c|c|c|c|c|c|c|}
\hline \multirow[b]{2}{*}{ Sample } & \multirow[b]{2}{*}{ NEC type } & \multirow[b]{2}{*}{$\mathrm{n}$} & \multicolumn{3}{|c|}{ LOS (days) } & \multicolumn{3}{|c|}{ Costs (2011 US\$) } & \multirow[b]{2}{*}{$\mathrm{p}$ value } \\
\hline & & & $\begin{array}{c}\text { Adjusted } \\
\text { mean }^{\mathrm{a}}\end{array}$ & $\begin{array}{c}95 \% \\
\text { CI (low) }\end{array}$ & $\begin{array}{c}95 \% \\
\text { CI (high) }\end{array}$ & $\begin{array}{c}\text { Adjusted } \\
\text { mean }^{\mathrm{a}}\end{array}$ & $\begin{array}{c}95 \% \\
\text { CI (low) }\end{array}$ & $\begin{array}{c}95 \% \\
\text { CI (high) }\end{array}$ & \\
\hline \multirow{2}{*}{$\begin{array}{l}\text { Without excluding } \\
\text { early deaths }\end{array}$} & Medical & 185 & 11.0 & 6.7 & 15.3 & 71,645 & 47,953 & 95,337 & $<0.0001$ \\
\hline & Surgical & 84 & 41.9 & 35.7 & 48.2 & 195,795 & 161,370 & 230,220 & 0.0001 \\
\hline \multirow{2}{*}{$\begin{array}{l}\text { Excluding deaths within } \\
\text { the first } 3 \text { days of life }\end{array}$} & Medical & 177 & 11.7 & 6.9 & 16.5 & 74,004 & 47,051 & 100,957 & 0.0001 \\
\hline & Surgical & 82 & 43.1 & 36.3 & 50.0 & 198,040 & 159,261 & 236,819 & 0.0001 \\
\hline
\end{tabular}

\footnotetext{
${ }^{a}$ The mean estimates for medical NEC and surgical NEC given here are the average incremental effects of each condition when other parameters in the Ordinary Least Squares model such as sex, race, payer status (Medicaid/private), death, and other comorbid conditions during the perinatal period are held constant.

$\mathrm{CI}$, confidence interval.
} 
Table 5. Estimation of Expected Neonatal Intensive Care Unit Costs Among Extremely Premature Infants Fed with Bovine Milk-Based Human Milk Fortifier Versus 100\% Human Milk Diets (Base-Case Scenario)

\begin{tabular}{|c|c|c|c|}
\hline Costs & Formula & BOV arm & HUM arm \\
\hline $\begin{array}{l}\text { Total costs for supplements } \\
\text { used per infant }\end{array}$ & $\begin{array}{l}C_{1}=([\text { median quantity of HMF } \\
\text { used } \times \text { unit cost of HMF }]+ \\
\text { [median quantity of supplement } \\
\text { used when mother's milk was } \\
\text { not available } \times \text { unit cost of supplement }])^{\text {a }}\end{array}$ & $\$ 195$ & $\$ 10,321$ \\
\hline $\begin{array}{l}\text { Average baseline } \\
\text { hospitalization } \\
\text { costs per EP infant }\end{array}$ & $\begin{array}{l}(1 \times \text { mean baseline cost estimates } \\
\text { of EP infants without NEC })^{\mathrm{b}}\end{array}$ & $\$ 207,378$ & $\$ 207,378$ \\
\hline \multicolumn{4}{|l|}{$\begin{array}{l}\text { Expected incremental costs } \\
\text { per EP infant }\end{array}$} \\
\hline Medical NEC & $\begin{array}{l}C_{3}=\left(p_{1}{ }^{a} \times \text { mean adjusted }\right. \\
\left.\text { incremental costs of } \mathrm{NEC}^{\mathrm{c}}\right)\end{array}$ & $\$ 11,798$ & $\$ 4,290$ \\
\hline Surgical NEC & $\begin{array}{l}\mathrm{C}_{4}=\left(\mathrm{p}_{2}{ }^{\mathrm{a}} \times[\text { mean adjusted }\right. \\
\text { incremental costs of surgical } \\
\text { NEC }- \text { mean adjusted } \\
\left.\text { incremental costs of medical NEC }]^{\mathrm{c}}\right)\end{array}$ & $\$ 12,583$ & $\$ 1,798$ \\
\hline $\begin{array}{l}\text { Total expected NICU costs } \\
\text { per EP infant }\end{array}$ & $T C=C_{1}+C_{2}+C_{3}+C_{4}$ & $\begin{array}{l}\$ 231,954 \\
(95 \% \text { CI } \$ 226 \\
457.74-\$ 237,451)^{d}\end{array}$ & $\begin{array}{l}\$ 223,787 \\
(95 \% \text { CI } \$ 222,053 \\
-\$ 225,521)^{\mathrm{d}}\end{array}$ \\
\hline $\begin{array}{l}\text { Net savings in hospital costs } \\
\text { per EP infant owing to HUM } \\
\text { arm over BOV arm }\end{array}$ & $T C_{\mathrm{BOV}}-T C_{\mathrm{HUM}}$ & \multicolumn{2}{|c|}{$(95 \% \text { CI } \$ 4,405-\$ 11,930)^{\mathrm{d}}$} \\
\hline
\end{tabular}

${ }^{\text {a }}$ Data obtained from Table 1.

${ }^{\mathrm{b}}$ Data obtained from Table 3 (second row).

${ }^{\mathrm{c}}$ Data obtained from Table 4 (second row).

${ }^{d}$ Represents the estimates calculated using 95\% CI limits for adjusted incremental costs of medical and surgical NEC as given in Table 4 (second row).

EP, extremely premature (gestational age $\leq 28$ weeks); NICU, neonatal intensive care unit.

milk-based diet is associated with a $63 \%$ lesser rate of NEC than that observed for the alternative bovine milk-based fortification of mother's milk and that the corresponding reduction in incidence of surgeries for NEC is more profound ( $86 \%)$. A net cost calculator developed based on these results shows a direct net savings of $\$ 8,167$ per infant receiving an exclusively human milk-based feeding strategy. The main drivers of cost savings in this model are the reduction in the rate of NEC and surgical NEC and their associated NICU costs. These savings could only be conservative for many reasons. For instance, we have not accounted for physician fees and post-treatment care costs of NEC in our model. Treating complications of surgery (for NEC) such as short bowel syndrome could be highly resource intensive because of the prolonged dependence of these patients on total parenteral nutrition. ${ }^{23}$ Survival of infants with intestinal failure following surgical NEC is associated with significantly prolonged hospitalization and higher utilization of hospital resources especially if small bowel transplantation, which might improve the chances of survival in such patients, is required. ${ }^{24}$ The expected costs of intestinal transplantation have been estimated to be in the range of $\$ 130,000-\$ 250,000$ depending on the type of allograft $^{25}$ besides other significant costs for pre- and posttransplant evaluation and testing, physician fees, lifelong immunosuppressant drugs, rehabilitation costs, etc. These costs are likely to rise further as a greater number of NEC/ intestinal failure survivors are generated by the current survival trends among EP infants. Given the huge reduction in the incidence of NEC and surgery for NEC (and hence short bowel syndrome) among infants who were fed a $100 \%$ human milk-based fortified diet, significant costs of postNEC complications can be averted.

\section{Economic value of NEC risk reduction}

Approximately $1.5 \%$ of live births in the United States, or 64,500 births, were very low birth weight (weighing $<1,500 \mathrm{~g}$ ) in 2007, and this represents a $20 \%$ increase in incidence of prematurity from $1990 .^{26}$ The mean incidence of NEC is reported to be $7-10 \%$ among EP infants. ${ }^{1}$ This implies that if we can achieve at least a 55\% reduction each in the rate of NEC and surgeries for NEC, we can avert 2,483-3,548 NEC cases among EP births annually. The corresponding savings that could be achieved for the U.S. population would be US\$ 212 million in hospitalization costs alone. Apart from these direct savings, prevention of NEC also entails indirect savings through prevention of NEC-associated mortality among newborns. The mortality rate due to NEC in the United States is estimated at 13.4 deaths per 100,000 live births. ${ }^{3}$ At the given mortality rate, about 587-839 newborns every year are expected to die owing to NEC. If we could achieve a $55 \%$ reduction in the rate of NEC (and conservatively assuming that feeding practices do not have additional direct benefit on improving mortality), about 323-461 lives could be saved annually. The economic value of prevention of mortality at birth is estimated to be very high considering that the survival rates are higher for infants. Studies on value of statistical life 


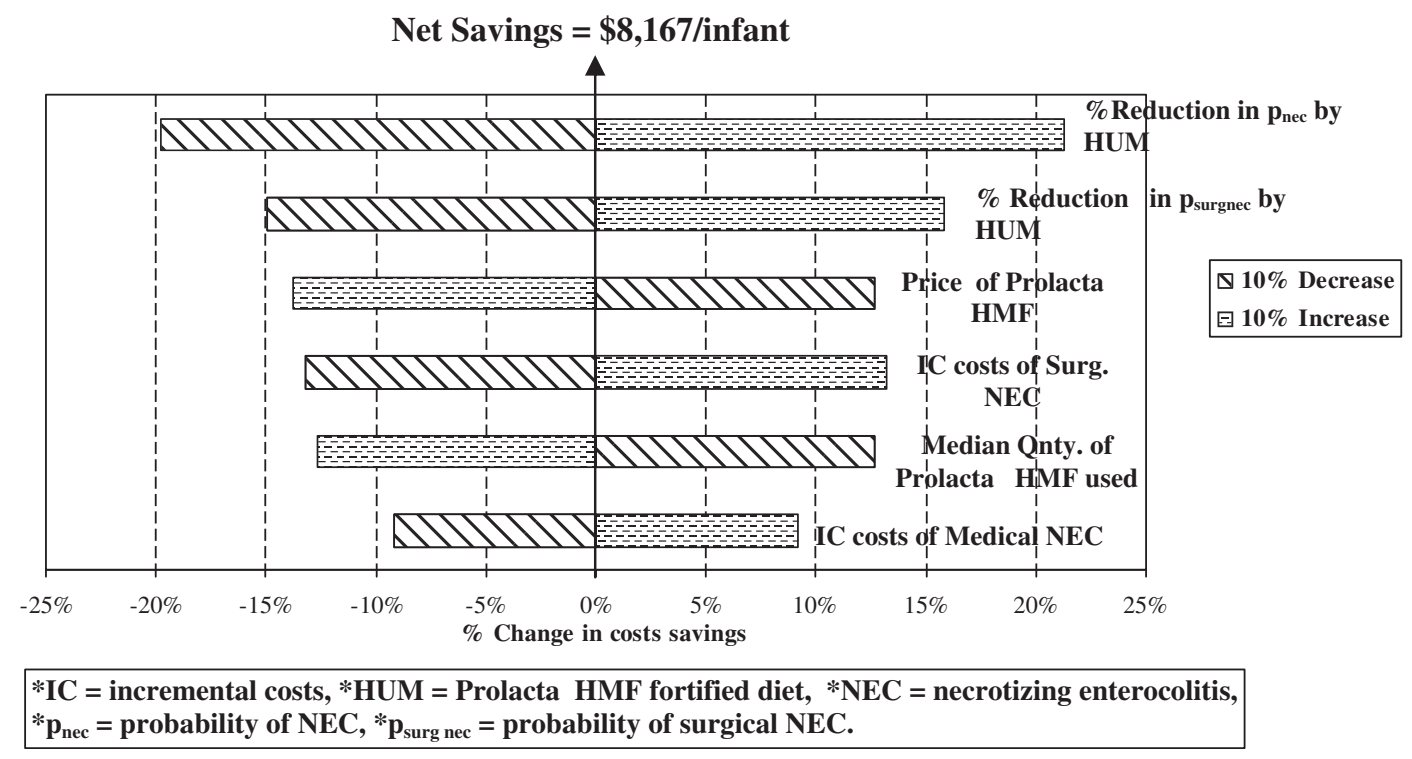

FIG. 1. One-way sensitivity analysis of costs savings to a $10 \%$ change in model parameters. There was a net savings of $\$ 8,167$ per infant. OSHPD, California Office of Statewide Health Planning and Development. IC, incremental costs; pnec, probability of NEC; psurgnec, probability of surgical NEC.

have placed a value of $\$ 5,000,000$ for the life of an infant for even small reductions in mortality risk. ${ }^{27}$ Thus the economic value of reduction in the risk of mortality due to NEC, given by the formula (number of lives saved $\times$ the economic value of life at birth), would be \$US 1.6-2.3 billion. Also, the total economic value incurred by the reduction in the risk of NEC, considering the direct costs and mortality costs averted, would be \$US $1.8-2.5$ billion.

Although this article carries important information to the neonatal community, the cost-effectiveness results should be interpreted with some caution. The results of our study are based on the only randomized trial conducted so far comparing bovine and donor HMFs. It could be possible that the incidence of NEC and surgical NEC observed among the 12 NICU units (11 in the United States and one in Austria) in the study of Sullivan et al. ${ }^{13}$ may or may not be representative of the universe of NICU units catering to the healthcare needs of EP infants. Given the lower frequencies of EP births and NEC in the general population, the costs of conducting such huge trials are prohibitive. Nevertheless, the primary driver of costs savings is, in fact, the percentage reduction in rates of overall NEC and surgical NEC in the HUM arm and not the absolute NEC rates. The highly significant results obtained for incidence of surgical NEC $(p=0.007)$ would mean that the results have less than 1 in 140 chance of being random. Second, the use of statewide hospital discharge data to evaluate the costs of NEC may be perceived as a potential limitation of the study in that the feeding patterns among infants in the discharge sample cannot be ascertained. At the time the clinical trial started, however, Prolacta HMF was not being used routinely in the United States; there were perhaps fewer than 10 NICUs that were using Prolacta HMF on a sporadic basis. Although real world data through chart review may have provided better data on proportions of milk use, these data would have been helpful only to magnify the cost difference we observed with a comparison to an exclusive human milk diet because the control group from the study of Sullivan et al. ${ }^{13}$ likely had a higher human milk intake compared with previous clinical experience or against national data. This observation was likely due to a positive effect that human milk research has on human milk usage. Overall we felt that the power in having large statewide data outweighed the benefit of greater resolution on feeding patterns that a significantly smaller and costly multicenter chart-review study would provide.

\section{Conclusions}

The NICU cost burden of NEC among EP infants is huge. Provision of an exclusively human milk diet composed of mother's own milk, or donor human milk when mother's milk is not adequately available, and fortified by donor HMF can result in saving net NICU resources and produce societal value by preventing infant mortality. The analyses presented in this article may assist healthcare providers and institutions to justify an increased use of human milk and human milk products to promote better health outcomes in EP infants.

\section{Acknowledgments}

We acknowledge that this research was funded by an unrestricted grant from Prolacta Bioscience to the University of Southern California. Under explicit university guidelines for sponsored research, Prolacta has had no editorial control over any part of this manuscript, although the company was allowed to review and comment on the initial draft.

\section{Disclosure Statement}

J.W.H. has consulted for Prolacta for work unrelated to the contents of this manuscript. J.H.K. has had a past affiliation with Prolacta Bioscience through support received 
for an industry-initiated clinical research study and unrestricted research funds to the Department of Pediatrics, University of California San Diego. V.G. declares no competing interests.

\section{References}

1. Thompson AM, Bizzarro MJ. Necrotizing enterocolitis in new borns: Pathogenesis, prevention and management. Drugs 2008;68:1227-1238.

2. Petrosyan M, Guner YS, Williams M, et al. Current concepts regarding the pathogenesis of necrotizing enterocolitis. Pediatr Surg Int 2009;25:309-318.

3. Horbar JD, Carpenter J, Kenny M, eds. Very Low Birthweight Database Summary. Vermont Oxford Network, Burlington, VT, 2007.

4. Fanaroff A, Hack M, Walsh M. The NICHD Neonatal Research Network: Changes in practice and outcomes during the first 15 years. Semin Perinatol 2003;27:281-287.

5. Breastfeeding and the use of human milk. American Academy of Pediatrics. Work Group on Breastfeeding. Pediatrics 1997;100:1035-1039.

6. Schanler RJ, Shulman RJ, Lau C. Feeding strategies for premature infants: Beneficial outcomes of feeding fortified human milk vs. preterm formula. Pediatrics 1999;103:1150-1157.

7. Lucas A, Cole TJ. Breast milk and neonatal necrotizing enterocolitis. Lancet 1990;336:1519-1523.

8. Sisk PM, Lovelady CA, Dillard RG, et al. Early human milk feeding is associated with a lower risk of necrotizing enterocolitis in very low birth weight infants. J Perinatol 2007;27:428-433.

9. Henderson JJ, Hartmann PE, Newnham JP, et al. Effect of preterm birth and antenatal corticosteroid treatment on lactogenesis in women. Pediatrics 2008;121:e92-e100.

10. Updegrove K. Necrotizing enterocolitis: The evidence for use of human milk in prevention and treatment. J Hum Lact 2004;20:335-339.

11. Schanler RJ. Evaluation of the evidence to support current recommendations to meet the needs of premature infants: The role of human milk. Am J Clin Nutr 2007;85(Suppl): 625S-628S.

12. Schanler RJ, Lau C, Hurst NM, et al. Randomized trial of donor human milk versus preterm formula as substitutes for mother's own milk in feeding of extremely premature infants. Pediatrics 2005;116:400-406.

13. Sullivan S, Schanler RJ, Kim JH, et al. An exclusively human milk-based diet is associated with a lower rate of necrotizing enterocolitis than a diet of human milk and bovine milkbased products. J Pediatr 2010;156:562-567.

14. Guner YS, Friedlich P, Wee CP, et al. State-based analysis of necrotizing enterocolitis outcomes. J Surg Res 2009;157:21-29.
15. U.S. Bureau of Labor Statistics. Consumer Price Index-All Urban Consumers-Medical Care. data.bls.gov:8080/PDQ/ outside.jsp?survey $=\mathrm{cu}$ (accessed December 2010).

16. Liang K, Zeger SL. Longitudinal data analysis using generalized linear models. Biometrika 1986;73:13-22.

17. Kurth T, Walker AM, Glynn RJ, et al. Results of multivariate logistic regression, propensity matching, propensity adjustment, and propensity-based weighting under conditions of nonuniform effect. Am J Epidemiol 2006;163:262-270.

18. Blakely ML. Surgical management of necrotizing enterocolitis and isolated intestinal perforation in premature neonates. Semin Perinatol 2008;32:122-126.

19. McGuire W, Anthony M. Donor human milk versus formula for preventing necrotizing enterocolitis in preterm infants: Systematic review. Arch Dis Child Fetal Neonatal Ed 2003; 88:F11-F14.

20. Boyd CA, Quigley MA, Brocklehurst P. Donor breast milk versus infant formula for preterm infants: Systematic review and meta-analysis. Arch Dis Child Fetal Neonatal Ed 2007; 92:F169-F175.

21. Meinzen-Derr J, Poindexter B, Wrage L, et al. Role of human milk in extremely low birth weight infants' risk of necrotizing enterocolitis or death. J Perinatol 2009;29:57-62.

22. Furman L, Taylor G, Minich N, et al. The effect of maternal milk on neonatal morbidity of very low-birth weight infants. Arch Pediatr Adolesc Med 2003;157:66-71.

23. Patel JC, Tepas JJ, Huffman SD, et al. Neonatal necrotizing enterocolitis: The long-term prospective. Am Surg 1998;64: $575-579$.

24. Vennarecci G, Kato T, Misiakos EP, et al. Intestinal transplantation for short gut syndrome attributable to necrotizing enterocolitis. Pediatrics 2000;105:E25.

25. Sudan D. Cost and quality of life after intestinal transplantation. Gastroenterology 2006;130(2 Suppl 1):S158-S162.

26. Hamilton BE, Martum JA, Ventura SJ. Births: Preliminary Data for 2007. National Center for Health Statistics, Hyattsville, MD, 2009.

27. Murphy KM, Topel RH. The Economic Value of Medical Research. University of Chicago Press, 1999. faculty .chicagobooth.edu/kevin.murphy/research/murphy \& topel .pdf (accessed December 2010).

Address correspondence to: Joel W. Hay, Ph.D.

Leonard Schaeffer Center for Health Policy E Economics University of Southern California University Park Campus, UGW-Unit A Los Angeles, CA 90089-7273

E-mail: jhay@usc.edu 


\section{Appendix}

Step 1. Identifying all extremely premature infant discharges in OSHPD 2007 data

$$
\text { 'n' }=5,502
$$

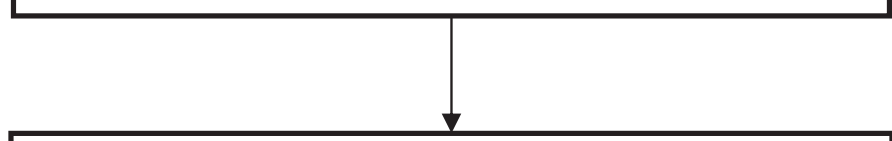

Step 2. Excluding discharges where costs are not reported resulting ' $\mathrm{n}$ ' $=4,697$

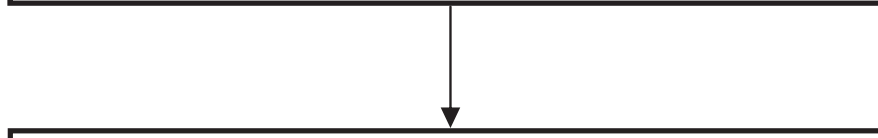

Step 3. Excluding discharges that are disposed to transfer to another hospital unit

resulting ' $\mathrm{n}$ ' $=3,287$

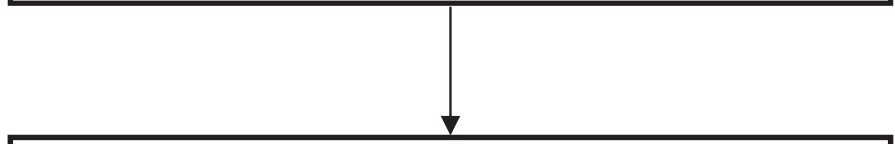

Step 4. Excluding discharges with daily cost $<\$ 100$

resulting ' $\mathrm{n}$ ' $=3,274$

Infants with no NEC: 3005, Medical NEC: 185, Surgical NEC: 84

Total Deaths: 1015 (31\%); Deaths occurring at < 3 days: 714

\begin{tabular}{|l|}
\hline Step 5. Final sample after eliminating infants who died within \\
3 days of life \\
resulting final 'n' $=2,560$ \\
• No NEC : 2,301 \\
- Medical NEC : 177 \\
\end{tabular}

FIG. A1. Preparation of the final analytic sample from 2007 California OSHPD discharge data. 